\title{
A Content Analysis of Serena Williams and Angelique Kerber's Racial and Sexist Microagressions
}

\author{
Cynthia M. Frisby \\ School of Journalism, University of Missouri, Columbia, MO, USA \\ Email: frisbyc@missouri.edu
}

How to cite this paper: Frisby, C.M (2017) A Content Analysis of Serena Williams and Angelique Kerber's Racial and Sexist Microagressions. Open Journal of Social Sciences, 5, 263-281.

https://doi.org/10.4236/jss.2017.55019

Received: April 25, 2017

Accepted: May 20, 2017

Published: May 23, 2017

Copyright $\odot 2017$ by author and Scientific Research Publishing Inc. This work is licensed under the Creative Commons Attribution International License (CC BY 4.0).

http://creativecommons.org/licenses/by/4.0/

\begin{abstract}
The primary purpose of this exploratory study was to determine if microaggressions regularly found in sport coverage were present in stories about two elite female tennis players. Microaggressions are subtle statements that unconsciously communicate denigrating messages to female athletes. In recent years, qualitative studies have introduced the types of microaggressions that female athletes experience. In the present study, a content analysis of 643 news stories was conducted in order to provide a quantitative measure of the frequency in which microaggressions appear in news stories about female athletes. Serena Williams, ranked number two in the list of top female tennis players, was selected because several qualitative studies show this female athlete of color is often the victim of racial slurs and epitaphs in news stories, as well as, news reports that feature insults to her physical appearance and body type. Angelique Kerber, the number one ranked female tennis player was selected in order to determine if an athlete of color receives more micro-aggresions than a top-ranked White female athlete. Data show that Serena Williams experienced more microaggresive themes related to gender roles and racial insults than Angelique Kerber $(\mathrm{p}<0.0000)$. It is concluded that future research should explore in greater depth the microagression aimed at Black female athletes in all levels of sports and their participation.
\end{abstract}

\section{Keywords}

Microaggressions, Racism, Discrimination, Restrictive Gender Roles, Microinsults, Racist and Sexist Insults

\section{Introduction}

Women in our western culture must be beautiful in order to be recognized. Why aren't women, particularly female athletes, recognized in our culture for their 
accomplishments? Specifically, why are the accomplishments of female athletes pushed aside in order to have their appearance and beauty showcased? What happens when a female athlete is muscular, strong, and attractive? This study relates to previous work in the area of gender-based microaggressions [1] [2] [3] [4]. This research will build on previous research by exploring how elite female athletes are represented in sports media. Little research has quantitatively characterized microaggressions as they may exist within female athletes and the sports industries or offer a content analysis of the themes found in news stories about female athletes. This study extends the literature by examining racial and sexist insults or microaggressions in news media between a White elite female athlete and a non-Hispanic African American elite female athlete. We sought to 1) characterize the themes published in news stories about two popular and internationally known elite female tennis players; 2) examine differences, if any, in the types of microaggressions that may be printed about female athletes with similar accomplishments and records to determine how media may treat female athletes on the basis of color. The study relies on microaggression literature and theory to provide theoretical and practical implications.

\subsection{Study Importance}

In a culture where the female body is always being critiqued, female athletes often seem to have to stand up to and challenge norms concerning their sexuality and gender identity. Research continues to show that female athletes are often covered negatively in the media and are often targets for comments that are degrading to and demeaning, especially when compared to male athletes.

Data presented in this study is needed in order to provide quantitative measures on the frequency of types of microaggressions found in news stories about Serena Williams and Angelique Kerber. Presently, several stories and articles can be obtained offering qualitative and/or editorials on the blatant mistreatment of female athletes, especially when compared to the ways media treat male athletes. Both theory on microaggression and a statistical method known as content analysis were used in this study to identify microaggression incidents in the news. As in [1], we will categorize microaggressions into six major subscales: (a) Sexual objectification, b) Second-Class Citizen, (c) Restrictive gender roles (d) Focus on traditional female appearance (e) focus on physical body and shape, and (f) use of racial insults or slurs. It is hoped that data obtained in this study will offer quantitative support for these microaggressions and will also confirm or disconfirm results provided in published qualitative studies [2]. For example, published qualitative work consistently shows us that female athletes of color experience microaggressions oftentimes dealing deal with their group membership (i.e., gorilla, etc.) [5] [6] [7]. We will test this hypothesis by analyzing the significance of the relationship between ethnicity and the insult theme related to racial insults or slurs. Will the frequency of microaggression themes related to group membership, appearance, and body shape be significantly higher for a Black female athlete than an equally talented White female athlete participating 
in the same sport?

\subsection{Why Serena Williams? Background and Purpose}

Serena Williams has experienced many attacks in the mass media as well as social media. Many of verbal attacks, it is theorized, may stem from her status as an uncommon tennis player: she is black, female, and playing in a white-dominated sport. The racialized, sexualized, dehumanizing comments about Serena Williams begs the question: how do these attacks and microaggressions make their way into media coverage? Researchers have found that complimentary commentary about Ms. Williams' athleticism is often grounded in stereotypes about black people, and black women specifically (masculine, unattractive, and overly sexual). For example, just before Serena won the French Open in June 2015, one news article compared the athlete to an animal, likened her to a man, and claimed that she was "frightening and horrifyingly unattractive." While it is very true that Serena Williams is black and very muscular, she is undoubtedly a very accomplished, talented and skilled player.

In a 2006 article about Serena, Dr. Peter Larkins, in an apparent attempt to compliment Williams, contributed his medical opinion in an interview with Australia's Herald Sun for a 2006 piece that compared the competitor's body type to Serena's and used the comparison to explain the competitor's loss. "It is the African-American race," he explained. "They just have this huge gluteal strength. ... Jennifer Capriati was clearly out of shape and overweight. With Serena, that's her physique and genetics." [8]. According to [4] this is an example of a microagression that attributes the victories of female athletes to the opponent's weaknesses, rather than to the winner's abilities and accomplishments.

In order to determine the extent to which news stories feature microaggressions toward women, we decided to select a top-ranked female tennis player who could be used to determine if Serena is the victim of more sexist attacks or if both women experience the same level of microaggressions simply because they are female athletes. The White female tennis player deemed as an appropriate and equal female athlete for this study Angelique Kerber, currently ranked the number one top female tennis player as of 2017.

Therefore, the primary purpose of this exploratory study was to see if microaggressions or insults are used in sports media to describe two popular topranked female tennis players. We hope to determine if these racial and sexist microaggressions are prevalent in magazine and newspaper sport coverage [9] [10] [11]. Kaskan and Ho's (2016) [1] theory of microaggressions aimed at female athletes was used to analyze results on sports coverage of Serena Williams and Angelique Kerber-top ranked female tennis players.

\section{Sexual/Racial Microagressions Aimed at Serena Williams}

While it is true that Serena Williams is black, very muscular, and a skilled tennis player, why do commentators seem to talk about these qualities in a way that seems demeaning? What we often find is commentary that equates Serena's athleticism to her ethnicity. 
In what was thought to be his attempt to compliment Serena, Dr. Peter Larkins shared his opinion about her body and compared her fitness to her competitors. In this article, Dr. Larkins was quoted as saying "It is the African-American race. "They just have this huge gluteal strength... Jennifer Capriati was clearly out of shape and overweight. With Serena, that's her physique and genetics." (see [12]). This is a perfect example of a microaggression focused on group identity and racial insult. This literature review will end with a more in-depth discussion about microaggression.

Media as well as tennis fans seem to have a very strange fascination with the size and shape of Serena's body. Reading some of the articles and comments online that have been made about Williams' body type, it seems that these comments expressed by journalists and sports commentators are directly related to the cultural norms concerning body image, physical attractiveness, and gender roles. It should be noted that journalists and sports commentators are not immune to the influences these norms have on our attitudes, opinions, and behaviors.

One important point must be made: Research on this topic reveals that it is not just White male commentators and journalists who make these types of microaggressive comments. We found an instance when Jason Whitlock, a black sports writer, criticized Serena Williams in a 2009 Fox Sports column. He attacked Ms. Williams for what he called her "oversized back pack." He went on to say that; "I am not fundamentally opposed to junk in the trunk, although my preference is a stuffed onion over an oozing pumpkin" [13]. Another sports commentator wrote; “Generally, I'm all for chunky sports stars ...but tennis requires a mobility Serena cannot hope to achieve while lugging around breasts that are registered to vote in a different US state from the rest of her" [14].

Add to the list, female athletes. In 2012, Serena's good friend, Danish tennis player Caroline Wozniacki, mocked Serena's body by stuffing her top and tennis skirt with towels at an exhibition match. Serena responded to those who thought the joke was in bad taste by saying, "I don't think she meant anything racist by it," but added, "If people feel [that it seems racist], she should take reason and do something different next time." (insert citation). Just a bad joke? One journalist wrote; "If Caroline truly wanted to impersonate Serena, she could have padded her legs and arms to represent Serena's muscled physique, but she targeted specific body parts-breasts and booty—for her little prank."

News stories depicting Serena and her sister, Venus, as "overwhelming" and "destroying" their opponents are significant and relevant to this literature review simply because stories incorporating these adjectives tend to rely on enduring stereotypes of the "dangerous" black body and the "strong black woman" [15]. Both Venus's and Serena's strong black female bodies were "described as 'pummeling', 'overwhelming' and 'overpowering' (apparently frail and powerless) white female opponents" [15]. It's true that sports metaphors include reverences to violence: "crushed," "killed," and "destroyed" aren't unusual words to hear when describing wins. But descriptions of Serena's power and the strength 
behind her victories have taken this type of hyperbole to another level-one that suggests she's absolutely unparalleled in her strength and capacity for violence, especially as compared with her white opponents.

Taken together, this literature helped to develop the main research question guiding the study:

RQ1: Will the frequency of insults related to group membership, appearance, and body shape be significantly higher for a Black female athlete than a equally talented White female athlete participating in the same sport?

\subsection{Theoretical Framework: Microaggressions}

A review of the literature on female athletes, the term "microaggressions" seems to describe commentary of female athletes in its everyday occurrence in news coverage. Microaggressions have been described as "subtle insults (verbal/nonverbal, and/or visual) [2]. Microaggressions are defined as "brief, everyday exchanges that send denigrating messages to [women] and people of color because they belong to a minority group [3]. Scholars believe that microaggressive messages are revealed by White individuals who may not be aware or recognize the bias and implications of their statements and/or behaviors. In other words, microaggressions are pervasive statements and behaviors that happen automatically. According [3], microaggressions happen so often that they are often dismissed and interpreted as being innocent, harmless jokes.

According to [4], microaggressions are revealed in three distinct forms-microassault, microinsult, and microinvalidation. A microassault is an "explicit racial derogation characterized primarily by a verbal or nonverbal attack meant to hurt the intended victim through name-calling, avoidant behavior, or purposeful discriminatory actions" (Sue et al., 2007) [3]. Examples include referring to someone as "colored" or "Oriental," "girl," "lady" and other descriptions according to their group and stereotype.

A microinsult, according to [3], is characterized by communications that convey rudeness and insensitivity and demean a person's heritage or identity. This type of microaggression represents subtle snubs, frequently unknown to the perpetrator, but clearly conveys a hidden insulting message to the recipient [3]. The context in which microinsults is made are very important. In addition, these can occur nonverbally by conveying the messages that women and people of color and their contributions are not important.

A microinvalidation is characterized by communications that exclude, negate, or nullify the psychological thoughts, feelings, or experiential reality of women or people of color [3]. For example, when Blacks are told that "I don't see color" or "We are all human beings," the effect is to negate their experiences as racial/ cultural beings [3].

\subsubsection{Microaggression: Sexual Objectification}

[1] also hypothesizes that female athletes tend to experience microaggressions as a result of being sexually objectified, assumed to be inferior to men, and are frequently told to behave as their gender role demands. Although microagressions 
exist for all women, [1] argue that microaggressions targeted at female athletes are a predominant source of psychological distress for female athletes. Objectification seen in the media undermines women's self-concept and self-esteem, creating feelings of shame and anxiety for women in sports, causing them to struggle. For purposes of the present study, we paid close attention to microaggressions involving sexual objectification, second class citizenship or the assumption of inferiority, and restrictive gender roles (Kaskan \& Ho, 2014). Sexual objectification of female athletes in the media, according to a review of the literature, is prominent and demonstrated in mediated messages that focus on the athlete's sexual desirability-even for elite athletes like Serena and Angelique. [16] found that female athletes are not taken as seriously as male athletes because of their portrayals in overtly sexual poses. [1] contended that female athletes experience microaggressions as a result of being objectified, assumed to be inferior to men, and told to behave as their gender role demands.

Sexual objectification of female athletes in the media, according to a review of the literature, will be prominent and demonstrated in mediated messages that focus on the athlete's sexual desirability-even for elite athletes like Serena and Angelique. [16] found that female athletes are not taken as seriously as male athletes because of their portrayals in overtly sexual poses. This literature led to the development of the second research question of the study:

RQ2: To what extent will printed stories about Williams and Kerber show higher frequencies related to objectification and other demeaning microaggressions related to physical appearance?

\subsubsection{Microaggression: Restrictive Gender Roles}

This particular microaggression is demonstrated in an overemphasis on femininity and associated with the sports that are perceived to be "feminine" like figure skating and gymnastics. When female athletes participate in masculine sports like basketball, media often times will downplay any traits of the athlete that are considered to be masculine. For example, in an article about Britney Griner, we learn that the WNBA offers make up and wardrobe sessions for all female basketball players-an attempt to make sure to protect their femininity. This type of practice reinforces the more tradition gender roles, and as we read in the Griner story it also alienates women who may have more masculine characteristics or those who participate in the ore masculine, aggressive sports. According to [1], adherence to gender roles may act as microaggressions ad perpetuate sexism and negative reactions toward female athletics and their given sport. The current study will build on this assertion by collecting quantitative data to confirm or disconfirm the frequency of these particular microaggressions in news stories.

\subsubsection{Microaggression: Racist/Sexist Jokes}

Framed as a joke, we often find pundits who will often criticize Serena Williams, a top elite female tennis player, as a humorless individual simply because she will not recognize racial "jokes" as being funny. Sexist and/or racist "jokes" in media 
are very subtle. For example, a top sports announcer made a so-called joke for example so-called "joke" is an example of a microaggression that women often experience. In October of 2014, Shamil Tarpishchev, the Russian Tennis Federation president criticized Serena Williams' appearance, likening her to being a man. Our next research question analyzed the relationship between frequency of microaggressions perceived as racist/sexist joke and the ethnicity of the female athlete. In other words, how many news stories will frame their references to race or gender in terms of simply being an innocent joke.

In addition to racist jokes, one search of youtube yields a plethora of videos making fun of the WNBA. According to literature on microaggressions, jokes like those made about female basketball players are often directed at individuals who belong to another race or gender and almost always have an underlying element of hostility to the humor. In other words, sexist or racist jokes in the form of microaggressions are often at risk of someone else's expense and offer the joker a way to indirectly express their anger or resentment towards another's race and/or gender. Microaggressions in the form of jokes are also a subtle way for the user to keep a marginalized group held down to the role of second-class citizen.

As mentioned earlier, most people are not at all aware that they rely on microaggressions typically because of cultural pressures to hide their anger or hostility, especially in a culture of political correctness. When challenged, or confronted about the subtle nature of a racist or sexist joke, we often here: "Oh, I was only kidding! Don't be so sensitive? Can't you take a joke?” Taken together the literature on racist and sexist jokes led to the development of our next research question:

RQ3: Black female Olympic athletes are more likely to be the target of racists jokes than White female Olympic athletes? And, will White female athletes be more likely to be the target of sexist jokes? In other words, what role does ethnicity play in the jokes and humor used by sports reporters?

\subsubsection{Focus on the Physical Shape and Appearance}

Media as well as sports fans seem to have a very strange fascination with the size and shape of a female athlete's body. Reading some of the articles and comments online that have been made about body type, we believe that the comments expressed by journalists and sports commentators are directly related to the cultural norms concerning body image, physical attractiveness, and ethnicity. It should be noted that journalists and sports commentators are not immune to the influences these norms have on our attitudes, opinions, and behaviors.

One important point must be made: Research on this topic reveals that it is not just White male commentators and journalists who make these types of microaggressive sexist comments. We found an instance when Jason Whitlock, a black sports writer, criticized Serena Williams in a 2009 Fox Sports column. He attacked Ms. Williams for what he called her "oversized back pack." He went on to say that; "I am not fundamentally opposed to junk in the trunk, although my preference is a stuffed onion over an oozing pumpkin." [13]. Another sports 
commentator wrote; "Generally, I'm all for chunky sports stars ...but tennis requires a mobility Serena cannot hope to achieve while lugging around breasts that are registered to vote in a different US state from the rest of her" [14].

We examined microaggressions found in news stories in which the reporter equates athleticism to an athlete's physique and/or natural ethnicity (e.g., body shape). We retrieved a story that was supposed to have complimented Serena Williams, or so it was reported. However, it was reported in this article that Dr. Peter Larkins shared his opinion about Ms. Williams' body and compared her fitness level her competitors. In the article, Dr. Larkins was quoted as saying "It is the African-American race. "They just have this huge gluteal strength ... Jennifer Capriati was clearly out of shape and overweight. With Serena, that's her physique and genetics" [8].

This literature led to the formulation of the last and final research question for this study:

RQ 4: Will Black female Olympic athletes be more likely than White female Olympic athletes to receive microaggressions related to physical features and body shape? And will White female Olympic athletes receive more microaggressions related to their physical attractiveness than Black female Olympic athletes?

\subsection{Research Questions}

Research questions were employed rather than hypotheses for this exploratory study:

RQ1: Will the frequency of insults related to group membership, appearance, and body shape be significantly higher for a Black female athlete than a equally talented White female athlete participating in the same sport?

RQ2: To what extent will printed stories about Williams and Kerber show higher frequencies related to objectification and other demeaning microaggressions related to physical appearance?

RQ3: Black female Olympic athletes are more likely to be the target of racists jokes than White female Olympic athletes? And, will White female athletes be more likely to be the target of sexist jokes? In other words, what role does ethnicity play in the jokes and humor used by sports reporters?

RQ 4: Will Black female Olympic athletes be more likely than White female Olympic athletes to receive microaggressions related to physical features and body shape? And will White female Olympic athletes receive more microaggressions related to their physical attractiveness than Black female Olympic athletes?

\section{Method}

Content analysis is an unobtrusive research method used by social scientists that has been applied to most forms of communication, such as newspapers, television and radio broadcasts [17]. Using a systematic coding of a text where two or more coders are used to assure results are not the subjective interpretations of one researcher. [18] contended intercoder reliability in content analyses should be near $90 \%$. 
In this study, we seek to answer questions about the frequency and relationship between microaggressions and ethnicity of two of the top-ranked female tennis players: Serena Williams and Angelique Kerber. We also wanted to explore the extent to which covert forms of sexual and racial microaggressions would be identified in the news coverage.

\subsection{Procedures}

A content analysis of news-stories was conducted on coverage that was published from 2011-2016. [19] describes content analysis as "a research technique for making replicable and valid inferences from texts (or other meaningful matter) to the contexts of their use" (p. 24). In this study, we used news articles as the text to be analyzed and coded from the articles the appearance of the sexual and racial microaggresions covered. By using content analysis as the research tool for the study, we were able to determine whether the media draw attention of a female athlete's ethnicity, group membership, appearance or body type in their published news stories. Data taken from this study might be used to determine how these microaggressions influence individual's attitudes and opionions of female athletes and their accomplishments.

Before coding the stories, we developed a codebook protocols that would help train coders in the process of coding the themes. The codebook specified key concepts, such as the coding unit of analysis, which specifies the part of the news story that is to be coded (e.g., words, sentences, paragraphs, entire story as well as the theme, which specified the larger part of the text that was to be used to interpret a given theme. The codebook also described the process of coding, including the definitions and examples of each theme and coding rules needed to guide the application of themes to codes from the sample. The codebook was developed with the research question (How often are microaggressions used in news stories about Black and White female tennis players?) in mind. The point of developing the codebook was to specify procedures that will allow us to accomplish the objectives envisioned for the study.

\subsection{Selection of Top Female Athletes}

We selected Serena Williams because she holds the most major titles in singles, doubles, and mixed doubles combined amongst active players. Ms. Williams has a solid record of achieving a total of 39 major title which ranks her third on the all-time list and second in the open era: 23 in singles, 14 in women's doubles, and 2 in mixed doubles. She is the most recent female tennis player to have held all four major singles titles simultaneously (2002-03 and 2014-15) and the third tennis player to have reached this record twice.

In order to ensure that the comparison between an African-American female athlete and a White athlete was similar, we selected Angelique Kerber. Angelique Kerber, a German tennis player is currently ranked number one in the world in women's singles tennis by the Women's Tennis Association (WTA). We selected the starting year of 2011 because Ms. Kerber rose to fame in 2011 at the $2011 \mathrm{U}$. 
S. Open. Then, she later went on to win an Olympic silver media while representing her country, Germany in the 2016 Summer Olympics.

\subsection{Unit of Analysis}

The primary source of data came from a media search of all news stories involving Serena Williams and Angelique Kerber that occurred over a period of five years (2011-2016). First, we used Lexis-Nexis Academic search to identify news stories involving the two female tennis players. Using the advanced search option, we then identified those events that occurred between January 2011 and December 2016.

The unit of analysis for this study was the news story. News stories that were focused on female tennis matches and broader issues with racial or gender elements of the two athletes were included in the study. If $50 \%$ or more of the time or space of a story was focused on just one of the female athletes (Serena or Angelique) the story was included in the study. Excluded stories were editorials, op-ed articles, website or online stories, and stories appearing in social media. Basically, if content appeared on a website at any time during the period but was originally produced prior to the start of our study, it was not included. Stories produced during the entire five year period were analyzed.

For print publications that also had websites, stories that appeared in both places were included in the study once, as long as the text of the article was identical in each media venue. Stories that appeared in more than one of the papers were counted once in our sample. For online news, every story that appeared on the home page of the site was coded, along with the top three stories on the home page. All national sports stories that met the above criteria were captured and coded.

\subsection{Search Terms and Criteria}

Using these coding procedures, we developed a dataset that included the date of the article, the name of the paper, the headline as it appeared in the story, the ethnicity of the athlete, and the group targeted. Although this study is specifically focused on comparing an African American top athlete with a White top female athlete, we did include stories that focused on Latina/o, Native American, Asian American and Pacific Islander groups.

This study examined newspaper and magazine articles from the 2011 through 2016. Articles were pulled from national, international and some local outlets. We searched databases that provided full-text continuous coverage. Using search term validation procedures described by [20], the following search terms were entered into the database: ${ }^{\star}$ top female tennis players, ${ }^{\star}$ Serena Williams, ${ }^{\star}$ Angelique Kerber, ${ }^{\star}$ female athletes, or ${ }^{*}$ insults, ${ }^{*}$ jokes, ${ }^{\star}$ appearance, ${ }^{*}$ outfit, ${ }^{*}$ clothing, ${ }^{*}$ physical attractiveness, ${ }^{\star}$ body image and or shape, ${ }^{\star}$ ethnicity or citizenship, and *objectification or body parts. The asterisk option retrieves words containing the letter string with all possible endings. The search yielded 643 total articles. 


\subsection{Coding Procedures}

Once the coding procedures were developed, we then coded each news story. We coded each story in multiple ways, including the type of story (e.g., match analysis, win/loss record, other) and the type of microaggression as identified by [3]. News stories that were found to fit one of the seven themes were coded $1=$ present. To avoid double coding, we sought to code the presence or absence of the nine themes. If, for example, four of the seven themes were present, we would code a "1" in the column for the appropriate theme.

Each coder trained with the senior researcher for approximately two weeks to learn the codebook for this project. All "housekeeping" variables (such as source, date, ethnicity of the athlete, type of sport, and identification of the microaggression themes) were tested on numerous occasions. Those variables each consistently reach a level of agreement of at least $80 \%$, and often the agreement was much higher. To demonstrate the validity of the coding rules that were specific for this project, inter-coder testing was conducted on all the complex variables.

Coders were trained on how to use the codebook, which described the themes that the content covered. Once trained, the three coders tested for reliability by comparing results of their separate analyses. After analyzing the same content, the coders met to discuss the coding of the themes to see if there were areas where the three did not agree. If it was determined that there was an error in the description of a theme within the content codebook, the category was edited so that both coders agreed on the terminology. The inter-coder reliability was $86 \%$. Intra-coder reliability was also tested for the three coders. To test for intra-coder reliability all three coders analyzed five news articles for content separately, and then a week later they analyzed the same magazines for content to see how consistent their coding methods were based on the content codebook. Coder one had $94 \%$ intra-coder reliability while coder two had $92 \%$ intra-coder reliability, and coder three had $96 \%$ intra coder reliability. All three intra-coder reliabilities were well above the reliability need to conduct a valid and reliable analysis of content.

\subsection{Primary and Secondary Outcome Measures}

The microaggression themes (categories) were derived from theory as developed by [1] which are relevant to the study at hand. For the data to be trustworthy and meaningful, we chose microaggressions as the theoretical framework because it is believed that this theory will help us understand the results that will arise from application of the microaggression themes to news stories.

The operational definitions of the microaggression themes were those defined in the [1] literature. The following themes were looked for within each media piece and noted in the number of times that each occurred in each article:

- Sexual objectification-Language reducing the athlete to her body or body parts; Worth is determined and measured by her sexual desirability.

- Second-class citizenship-Language that places importance on the athlete's ethnicity and group membership; The athlete is only focused on part of a 
whole rather than an individual. "Team above self" is an accurate analogy for this variable.

- Use of racist/sexist language- Words that demean the athlete based on being a woman or being a woman of color; Microaggressions based on racism and sexism that add no value to details of the event or athlete being covered.

- Restrictive gender role- Language that refers to acceptable behaviors associated with one's gender and shows an overemphasis on femininity.

- Sexist humor/jokes

- Focus on traditional feminine appearance-Language that focuses on hair, makeup, outfits or overall feminine composure.

- Focus on physical body shape/image

\section{Data Analysis}

We used a content analysis in order to study media portrayals of one Black and one White top-ranked, elite tennis player. Portrayals included a range of sources, such as newspapers, magazines, online news papers, and online magazines. We drew samples from selected sources that fell within selection boundaries such as timeframe (2011-2016), genre (sports), and topic (microagressions and insults of top, professional female athletes).

To analyze the data, we chose to rely on a quantitative form of content analysis, where the themes were coded and then we counted the occurrence of themes in our codebook (e.g., the number of times a particular microaggression was found in the story). For this exploratory research, we believed that research which might reveal unique yet overlapping concepts crucial to understanding how the media produce, portray and reproduce ideas about female athletes was crucial and much-needed in published research.

To analyze our data and address the research questions, the researcher used Chi Squares for association to determine the relationship between ethnicity of the female athlete and the frequency of particular types of microaggressions. This study was primarily interested in determining whether ethnicity of a female athlete is associated with the type of microaggressions they receive in sports media. We wanted to gauge the strength of the association, so Cramer's V for association was deemed the most plausible method of data analysis.

\section{Results}

The frequency data produced a general overview of the information obtained. This information is shown in Table 1. Between January 2011 and December 2016 a total of 643 articles were found containing references to Serena Williams and Angelique Kerber. Findings outlined in Table 1 reveal that the most common microagressions using the framework from [2] were microassaults while fewer were microinsults. Microassaults included the numerous reports of race, gender, and other mentions of racism. For example, we ran across a news article with the headline "Serena Williams subjected to racist, sexist remarks following French Open victory." This article was published in 2015 and the first paragraph read as follows: 
Table 1. Frequency of Microaggressions in News Stories about Serena Williams and Angelique Kerber.

\begin{tabular}{|c|c|c|c|c|}
\hline \multirow{2}{*}{$\begin{array}{c}\text { Microaggression themes } \\
\text { Sexual objectification }\end{array}$} & \multicolumn{2}{|c|}{ Top Female Tennis Player } & \multirow[b]{2}{*}{$\chi^{2}$ (Chi-Square) } & \multirow[b]{2}{*}{$\mathrm{P}$ value } \\
\hline & Serena & Angelique & & \\
\hline Present & 160 & 5 & 0.04 & 0.84 \\
\hline Not present & 465 & 13 & & \\
\hline \multicolumn{5}{|l|}{ Second-class citizen } \\
\hline Present & 70 & 0 & 2.26 & .13 \\
\hline Not present & 555 & 18 & & \\
\hline \multicolumn{5}{|l|}{ Restrictive gender role } \\
\hline Present & 114 & 3 & $107.46^{\star * *}$ & 0.0000 \\
\hline Not present & 511 & 15 & & \\
\hline \multicolumn{5}{|l|}{ Physical appearance } \\
\hline Present & 49 & 0 & 1.53 & 0.22 \\
\hline Not present & 576 & 18 & & \\
\hline \multicolumn{5}{|l|}{ Physical body type } \\
\hline Present & 288 & 10 & 0.63 & 0.43 \\
\hline \multicolumn{5}{|l|}{ Racial/sexual Insults } \\
\hline Present & 77 & 0 & $75.5^{* * *}$ & .0000 \\
\hline Not present & 18 & 40 & & \\
\hline
\end{tabular}

Note: ${ }^{\star}=\mathrm{p}<.01,{ }^{* *} \mathrm{p}<.001,{ }^{* *} \mathrm{P}<.0001 ;$ Numbers appearing in the table are the raw numbers taken from the news stories coded.

Serena Williams is known for her muscular build and aggressive playing style on the tennis court, traits that have helped her achieve sports stardom. However, despite winning the French Open for the third time in her illustrious career on Saturday, Williams continues to be on the receiving end of racist and sexist remarks about her body and appearance. Sure, the brunt of the ugly comments comes from online trolls, but interestingly, Jenee Desmond-Harris of Vox Sports, points out, many racist and sexist comments come from those in the media, and are thinly veiled."

RQ1: How frequent do microaggressions in terms of assumptions of inferiority, second-class citizenship, restrictive gender roles, and sexual objectification appear in sports news and/or print media content about Serena Williams and Angelique Kerber?

\subsection{Microaggressions: Racist/Sexist Language and Jokes}

Many media outlets and sportscasters, according to our results, described Serena Williams as an "ugly, bulky, animalistic man." In lieu of reporting on the newsworthy item, the event that really matters-her remarkable winning recordmediated messages in news centered around Serena's body, her blackness, and clothing. This focus often noted is common in stories about Serena Williams, a 
female athlete who has been breaking records in the tennis world since 1999. Yet, despite her record-breaking accomplishments, her athletic prowess, and her toned body, Ms. Williams has been the target of racist and sexist attacks for the over a decade. This study found a significant relationship showing that sport news, online commentators, and journalists often describe Serena Williams as a "gorilla," as "manly" and as "savage".

We also coded a news story that showed a fan dressed in blackface held a sign saying "Keep Calm and be Serena." Another story showing this theme in media was an article printed in 2014. The story was about Shamil Tarpischev, the Russian Tennis Federation President, who referred to Venus and Serena as "frightening" and jokingly called them brothers.

RQ2: Will differences be found in microaggressions aimed at Serena Williams, an African American female athlete and Angelique Kerber, a White female athlete? Or will the frequency of microaggressions be similar since both are top ranked female athletes?

Angelique Kerber, a 28 year-old German female athlete, won her second Grand Slam title of the year at the US Open in 2016. However, our data collection obtained fewer than 20 negative articles about Ms. Kerber. In fact headlines about Kerber's win over Williams were: "Kerber now number 1," "In a year of stunners, sports goes along for the ride," "How Serena became the goat and a bad loser," "Nothing negative for Kerber as she beats Siniakova at China Open ...," and "Serena Williams loses to Strong Blonde Lefty German Angelique Kerber." This last headline is a perfect example of a sexist microaggression in that it uses "blonde lefty" as a descriptor of Angelique Kerber.

In another headline, "Despite decades of racist and sexist attacks, Serena Williams keeps winning," analysis of the headline and news story shows that the article was clearly focused on Angelique Kerber's win, yet the journalist focused primarily on the microaggressions leveled against Serena Williams when making comparisons to her competitor, Angelique Kerber. Although the frequency of the second-class citizenship microaggression did not reach significance, it should be noted that seventy news stories were found that support the idea that journalist and commentators seem to place more importance on ethnicity and group membership when writing about Serena while zero articles were found about Angelique's German identity and group membership $(\mathrm{p}=0.13)$.

RQ3: What types of microaggressions are printed in news stories about female tennis players? And will the types of microaggresive themes differ based on ethnicity of the female athlete?

\subsection{Microaggressions: Second Class-Citizenship and Racist Jokes}

Although not nearly as pervasive as microassaults, several incidents rose to the level of microinsults, conveying messages of rudeness and demeaning Serena and to some extent people of color (see Table 1). One example of the racial insult can be found in the headline of a news story in 206; "Announcer got fired for allegedly calling Serena Williams 'gorilla', now she wants to sue ESPN for 
wrongful termination." Another article appearing in November 2015 had a headline that read: "Serena Williams Called Gorilla by ESPN Commentator." The insult microaggression theme in these news stories, like the blackface fan incident at the Australian Open, has not been recognized by journalists as being harmful and inappropriate.

In analyzing the articles, it seems as if journalists and sports commentators are inadvertently sending out confirmation of the insult and slur that compares people of color to gorillas. We also coded a story that was published in January of 2016. This story (and many others) was about two fans who were spotted wearing blackface during Serena Williams' match at the Australian Open. One sports commentator tweeted; “There's a Serena Williams fan in the crowd ... wearing blackface." This is problematic and a perfect example of racial insults as microaggressions because it is possible that the appearance of these slurs and offenses in news stories may actually reinforce the idea and perception that calling people of color gorillas and dressing in blackface is just a joke. Other examples of this microaggression can be found in other forums, like politics, especially when pundits referred to former President Obama and his family as gorillas. More times than not, when their insult was revealed the perpetrator always made the comment that it was "simply a joke and wasn't meant to cause harm."

\section{Discussion}

The goal of the present study was to obtain a quantitative measure on the frequency of types of microaggressions found in news stories about Serena Williams and Angelique Kerber. Both theory and statistical methods were used in this study to identify microaggression incidents in the news and to categorize them into six major subscales: (a) Sexual objectification, b) Second-Class Citizen, (c) Restrictive gender roles (d) Focus on traditional female appearance (e) focus on physical body and shape, and (f) use of racial insults or slurs. The data obtained in this study support both theoretical literature [3] and qualitative studies [2] [4], which posit that female athletes of color experience microaggressions that deal with their group membership, gender roles, and racial slurs (i.e., gorilla, etc) in their everyday lives. Coding these themes appeared to be easily identifiable to the trained coder, and, those instances were quickly noted as being racially related.

Results provided evidence of reliability through satisfactory Krippendorf reliability scores. We found that the themes used to measure sub-categories involved in microaggressions prove to be adequate measures of microaggressions leveled toward female athletes.

Microaggressions are subtle insults (verbal, nonverbal, and/or visual) directed toward female athletes, often automatically or unconsciously (Kaskan \& Ho, 2016). Racial microaggressions, or unconscious and subtle forms of racism found in sports media, though pervasive, are seldom investigated. The findings from the current study regarding microaggressions related to race in sports media mirror to some extent themes suggested in [4]'s research and review of mi- 
croaggressions. The sports news stories obtained in the current study noted that the two top female tennis players, Serena Williams and Angelique Kerber, are often insulted in sports media and these insults relate to their race, appearance, and body shape. Data obtain also provided support of microaggressions related to restrictive gender roles. These stories about gender roles seemed to perpetuate ideas of what it means to be masculine or manly versus feminine.

\subsection{Limitations}

The current study has a few limitations that are worth noting. We believe that it is very likely that there are more than 643 stories involving Serena Williams and Angelique Kerber. It is possible that the search terms we used did not allow us to capture themes that may have actually been present in the story. We recognize that themes such as sexual objectification may not be considered newsworthy making other incidents to get covered at much higher frequencies. It is possible that some events and stories may have been published but simply did not get covered by the news. We also recognize that solely including news stories of the top female tennis players may also be limiting because microaggressions do not happen to one women's sport more than others.

\subsection{Future Research Directions and Implications for Practice}

There are many implications that this study has for sociologists, journalists, sports journalists, and scholars in women and gender studies. First and foremost, is the need to identify and quantify the number of microaggressions as provided by Sue and colleagues $(2007,2008)$ [2] [3] that consumers may be exposed to on a daily basis. While this is an exploratory study, it was concluded that obtaining some measure of the number of these themes that people are exposed to could be a starting point and useful measure to ultimately figure out how exposure to these microaggressive themes might impact men and women, athletes and non-athletes, young boys and girls, and coaches, sports psychologists, and other related professions.

Future research should use data in this study to examine the impact that exposure to national news stories that have microaggressive themes have on individual well-being, particularly their mental and physical health. One of the main limitations regarding previous microaggression studies is that they use qualitative methods. Many editorials found in the news are essentially qualitative descriptions of the perception that Serena Williams, for example, is a victim of racism and sexism in the professional tennis world and that those microaggressions carry over to the fans of professional tennis. Using content analysis methods and perhaps experimental methods to measure microaggressions can assist researchers in investigating the relationship of microaggressions with various mass communication constructs.

Second, we would like to offer the suggestion that microaggressions can be identified and are able to be coded and label them as being race and gender- related. This is important because some critics may assert that identification of 
microaggressions in print media may be difficult to identify because of its subjective nature. Perhaps future empirical studies can examine the perceptions of microaggressions and the implicit bias that may incite these behaviors. Studies may examine how racial identity, ethnic identity, or gender may influence one's ability to recognize microaggressions, and further research may explore how microaggressions may impact self-esteem, coping mechanisms, and self-presentation of the perpetrator.

There needs to be additional studies determining if microaggressions are present in other forms of sports and media coverage of women and men in sport, since this was one of the first studies examining the relationship between microaggressions and sports coverage about professional female athletes. Exploratory studies on media sports coverage in a variety of areas would seem appropriate. These studies could examine content within specific media sites on varying sports, and/or analyze content from multiple media vehicles on either one sport or a variety of sports. Research on sports coverage could also examine for quantitative and qualitative differences between mainstream sports media, those covering a variety of women's sports and men's sports.

\section{Implications for Journalists and Communications Practitioners}

With the potential research that may emerge with this exploratory research, there are many implications for practice as well. Sports reporters must be aware of the various types of microaggressions that their athletic clients experience as well as the ways that their clients cope with such instances. Examining the microaggressions that appear in media can actually be used to help conceptualize an athlete's mental problems and ability to perform.

We contend that results obtained in the current study seem to suggest that racial and gender related microaggressions are active manifestations in media and sports news. Microaggressions aimed at female athletes, we believe, appear to reflect the active manifestation of worldviews that create, foster, and enforce racism, sexism while also explaining the less that positive portrayals in news media about female athletes. Because people want to and are motivated to see themselves as good and decent people, research tells us that realizing that we may harbor these negative and hostile ideas and express those ideas through microaggressions may be very disturbing and uncomfortable. This cognitive dissonance often results in denying, diminishing, rationalizing as well as avoiding attempts to look within ourselves and recognize these biases and hostile feelings. Yet, research suggests that journalists, scholars, sports managers, sports promoters, reporters, announcers, and others involved in the sports news industry are not immune from inheriting the racial and gender biases of our society. People must recognize that we all have been socialized into a culture where racist and sexist attitudes, beliefs and behaviors exist. Many of the messages that contain microaggressions related to race and sex are often outside the level of conscious awareness, thus we find these thoughts and opinions in media, messages that unintentionally demean and discriminate against others, namely women and 
minority athletes.

According to their website, SMR suggests that all sport journalists, reporters, media and editors do the following $\left({ }^{*}\right.$ note information taken from their website):

- Commit to Non-Sexist Communications. A great resource for both sport managers and the sports media is Images and Words, a position paper published by the Women's Sports Foundation. This should be a resource used by every sports information director, communications officer and sports writer who is committed to non-sexist publications and writing.

- Publications. Journalists need to play careful attention to photos and words in all mediated communications. Sexist language and image stereotyping is never intentional but a reflection of culturally ingrained habits.

- Media Cultivation. Research also shows that what gets into a newspaper has little to do with "public interest" and is more about what interests the sports editor.

- Media Training. All journalists, scholars, researchers, sports reporters, anyone interested in this industry should be required to take training courses with regard to sexist and racist language and re-write stories where these violations have been published.

- Public Interest Stories. All print and electronic media are interested in public interest stories. Sports reporters should constantly write stories about athletes, especially women that go beyond looks, sexual objectification, body shape, ethnicity, and their violation of gender roles.

\section{Acknowledgements}

I would like to thank reviewers of this journal who provided insight and expertise that greatly assisted the research, although they may not agree with all of the interpretations/conclusions of this paper. Comments were extremely helpful in re-organizing and strengthening the theory as well as implications of this study.

I would also like to thank reviewers of the journal Studies in Journalism and Communication for assistance with the journal title, method, and other comments that greatly improved the manuscript. Your comments on an earlier version of the manuscript were significant.

Last, but not least, I would like to thank three individuals who provided help during the research (e.g., gathering literature, training, and coding or proof reading the article, etc.); Thank you to Isabel Crane, Tyler Parton, and Ikram Omar. I couldn't have done this without you. Your hard work and dedication paid off!! Our research was published!

\section{References}

[1] Kaskan, E.R. and Ho, I.K. (2016) Microaggressions and Female Athletes. Sex Roles, 7, 275-287. https://doi.org/10.1007/s11199-014-0425-1

[2] Sue, D.W., Nadal, K.L., Capodilupo, C.M., Lin, A.I., Torino, G.C. and Rivera, D.P. (2008) Racial Microaggressions against Black Americans: Implications for Counsel- 
ing. Journal of Counseling \& Development, 86, 330-338. https://doi.org/10.1002/j.1556-6678.2008.tb00517.x

[3] Sue, D.W., et al. (2007) Racial Microaggressions in Everyday Life: Implications For Clinical Practice. American Psychologist, 62, 271-286.

https://doi.org/10.1037/0003-066x.62.4.271

[4] Sue, D.W. (2010) Microaggressions in Everyday Life: Race, Gender, and Sexual Orientation. John Wiley \& Sons, Hoboken.

[5] The Conversation Africa (2016) Comparing Black People to Monkeys Has a Long, Dark Simian History. Huffington Post, 29 February 2016.

[6] Hund, W.D., Mills, C.W. and Sebastiani, S. (2015) Simianization: Apes, Gender, Class, and Race. Vol. 6, LIT Verlag, Münster.

[7] Duggan, M. (2014) Experiencing Online Harassment. Pew Research Center, 22 October 2014.

[8] Stevens, M. (2006) Size up Serena Williams at Your Own Risk. Sun Herald, 57.

[9] Bishop, R. (2003) Missing in Action: Feature Coverage of Women's Sports in Sports Illustrated. Journal of Sport \& Social Issues, 27, 184-194.

[10] Higgs, C.T., Weiller, K.H. and Martin, S.B. (2003) Gender Bias in the 1996 Olympic Games. A Comparative Analysis. Journal of Sport \& Social Issues, 27, 52-64. https://doi.org/10.1177/0193732502239585

[11] Vincent, J., Pedersen, P.M., Whisenant, W.A. and Massey, D. (2007) Analysing the Print Media Coverage of Professional Tennis Players: British Newspaper Narratives About Female Competitors in the Wimbledon Championships. International Journal of Sport Management and Marketing, 2, 281-300. https://doi.org/10.1504/ijsmm.2007.012406

[12] Desmond-Harris, J. (2015) Serena Williams, Racism, and Sexism (Double Participation). Ethnic Studies 101, 11 September 2015.

[13] Whitlock, J. (2009) Serena Could be The Best Ever, But... Foxsports.com

[14] Norman, M. (2006) Serena's Loyal Supporters. The Telegraph.

[15] Vincent, J. (2004) Game, Sex, and Match: The Construction of Gender in British Newspaper Coverage of the 2000 Wimbledon Championships. Sociology of Sport Journal, 21, 435-456. https://doi.org/10.1123/ssj.21.4.435

[16] Daniels, E.A. (2012) Sexy versus Strong: What Girls and Women Think of Female Athletes. Journal of Applied Developmental Psychology, 33, 79-90.

[17] Krippendorff, K. (2004) Content Analysis: An Introduction to Its Methodology. Sage, Thousand Oaks, CA.

[18] Carey, J.W., Morgan, M. and Oxtoby, M.J. (1996) Intercoder Agreement in Analysis of Responses to Open-Ended Interview Questions: Examples from Tuberculosis Research. Field Methods, 8, 1-5. https://doi.org/10.1177/1525822x960080030101

[19] Krippendorff, K. (2007) Computing Krippendorff's Alpha Reliability. Dep. Pap. $A S C, 43$.

[20] Stryker, J.E., Wray, R.J., Hornik, R.C. and Yanovitzky, I. (2006) Validation of Database Search Terms for Content Analysis: The Case of Cancer News Coverage. Journalism \& Mass Communication Quarterly, 83, 413-430.

https://doi.org/10.1177/107769900608300212 
Submit or recommend next manuscript to SCIRP and we will provide best service for you:

Accepting pre-submission inquiries through Email, Facebook, LinkedIn, Twitter, etc. A wide selection of journals (inclusive of 9 subjects, more than 200 journals)

Providing 24-hour high-quality service

User-friendly online submission system

Fair and swift peer-review system

Efficient typesetting and proofreading procedure

Display of the result of downloads and visits, as well as the number of cited articles Maximum dissemination of your research work

Submit your manuscript at: http://papersubmission.scirp.org/

Or contact jss@scirp.org 